\title{
ETNOGRAFÍA DE LOS ETNÓLOGOS: Experiencias del (Re) Encuentro Internacional de Arqueología y Etnohistoria en Cochabamba
}

\author{
Juliane A. MÜLLER SEBORGA \\ UCB-Cochabamba, Bolivia. \\ julianeangie@yahoo.com
}

\begin{abstract}
ETHNOGRAPHY ETHNOLOGISTS: Experiences of (Re) International Meeting of Archaeology and ethnohistory in Cochabamba
\end{abstract}

Resumen: A partir del trabajo de campo, de la exposición de trabajos arqueológicos, históricos y antropológicos y los recesos durante seis días, se presenta ante nuestros ojos un ritual donde se observan situaciones sociales de segregación y etnocentrismo por parte de la élite y los "iniciados", al grupo de novatos que presenta su ofrenda para acceder a la información; donde los conocimientos son un bien material e inmaterial en una comunidad pequeña, de rituales imperecederos y que siente gran atracción hacia el "otro exótico". El presente trabajo se constituye en una etnografía crítica que toma como objeto de estudio la comunidad esporádica que se forma en el Encuentro Internacional de Arqueología y Etnohistoria en Cochabamba, Bolivia en 2015. Donde los investigadores se convierten en los "sujetos de estudio", con la intencionalidad de volcar los papeles que por tanto tiempo han permanecido en el juego de alteridad de investigador/sujeto/objeto en Bolivia y reflexionar sobre el etnocentrismo epistémico persistente.

Abstract: From fieldwork, exhibition of archaeological, historical and anthropological work and breaks for six days, before our eyes a ritual where social segregation and ethnocentrism are observed by the elite and the "initiated", the group of apprentices who presents his offering for access to information; where knowledge is a material and immaterial well in a small community, rituals and timeless feel great attraction to the "exotic other". This work constitutes a critical ethnography that takes as its object of study the sporadic community that forms in the International Meeting of Archaeology and Ethno history in Cochabamba, Bolivia in 2015. Where researchers become the "study subjects" with the intention of turning the papers for so long have remained in the game otherness of researcher / subject / object in Bolivia and reflect on the persistent epistemic ethnocentrism.

Palabras clave: Etnografía Crítica, Ciencias Sociales, Bolivia, Ruptura Epistémica Critical Ethnography, Bolivia, Social Science, Epistemic Break 
Un ritual que sucede cada cierto tiempo': se mandan las convocatorias, programas o afiches, que reúne a los investigadores en las áreas de Historia, Arqueología y Antropología, tal como otros congresos y encuentros del mismo tipo.

Como parte de generar una nueva forma de antropología experimental, es que se realizó un trabajo etnográfico en el Encuentro, con las herramientas clásicas de la etnografía: diario de campo, entrevistas y observación participante (cf. Hammersley y Atkinson, 1994 y Guber, 2001).

Al principio uno se emociona: ahí están los nombres de aquellos que sólo se conoce por libros y de los que difícilmente se pueden pronunciar correctamente sus apellidos; pero más adelante la primera advertencia se lee en el afiche: el precio de la entrada para el oyente. ¿Qué significa esta seña? La respuesta llega casi inmediatamente, significa que este "encuentro" no es para todos, que nada tiene que ver con la democracia epistémica, que está dirigido para aquellos que dispongan de determinada situación económica, de determinados contactos o que son suficientemente "fanáticos" para presentar una ofrenda, que no responde al "nivel de vida" general de la población. Esta ofrenda, es a la vez un sacrificio ritual que tiene dos dimensiones: el dinero y el tiempo.

Esta segunda dimensión está la advertencia que se refiere al horario de las conferencias, que son de 8:30 a 12:30 y de 14:30 a 18:30 (horario de oficina) en los cinco días laborales de la semana. Esto excluye a los que, como la mayoría de la gente, estudia o trabaja fuera de lo que concierne a este ámbito de las "ciencias sociales".

Estas advertencias o señas significan una cosa: No se desea una participación democrática, incluyente o pública; no se desea que los "extraños" se inmiscuyan dentro de este mundo privado, casi secreto, que mantienen los investigadores sociales, en este caso, de este círculo de los investigadores que se presentaron del 24 al 29 de agosto de 2015 en la ciudad de Cochabamba. Aquellos que solicitan el "privilegio" de presenciar el encuentro, deben presentar un "sacrificio", como sucede en la mayoría de los casos. Para algunos este es un ritual de iniciación: Para el exponente novel y para el estudiante primerizo. También puede ser un rito de paso, de una categoría (de simple observador, por ejemplo) a una superior (a disertante).

Este elitismo, porque no puede llamarse de otro modo, forma parte de una especie de ritualidad que como todo rito corpóreo, significante y simbolizante, reactualiza un "mito". Este mito se basa, como podemos concluir después de un proceso interpretativo, en la "veracidad de la realidad científica" en las disciplinas de la Historia, Arqueología y Antropología y que se traduce en la imagen cotidiana de un club privado, un círculo "místico" que se reúne cada año o cada cierto tiempo en diferentes partes del mundo, para contarse los chismes más novedosos, es decir, reactualizar las frases y relatos que contiene el mito.

A lo largo del encuentro se reconocieron distintas figuras:

-La élite como tal, las "huacas sagradas" por decirlo de algún modo. Categoría compuesta por los investigadores más reconocidos, de larga trayectoria y de varias publicaciones; que son constantemente asediados y solicitados por las siguientes categorías.

-Los investigadores titulares, que son parte del “círculo místico" donde confluyen todas las nacionalidades que aprovechan los recesos para comunicarse, de manera más informal, de las últimas noticias sobre sus investigaciones. En

1 Esta Investigación está realizada en el Encuentro Internacional “Arqueología y Etnohistoria en los Andes y Tierras Bajas. Dilemas y Miradas Complementarias”. Cochabamba, Bolivia. Agosto de 2015. Palacio Portales de la Fundación Simón I. Patiño. 
esta categoría también se usan diferentes idiomas: español, inglés, francés y alemán.

-Los investigadores honorarios. Son los nuevos miembros, compuestos por discípulos de la élite y recientes Phd. (Doctores) en su área, investigadores en asenso y medianamente reconocidos.

-Los investigadores Junior. Oyentes cuyos trabajos comienzan a surgir o a ser conocidos, o que en su caso, son ya reconocidos pero no dentro de este ámbito en particular. Los sujetos dentro de esta categoría se caracterizan por buscar la atención o conversación con las dos primeras figuras, ya sea con fines de curiosidad académica o para ganar reconocimiento dentro del grupo. Se encuentran en un punto medio, el limbo. No son parte todavía del círculo, tampoco son partícipes del conocimiento total, a través de su actitud y su nivel de experiencia es que las huacas valorarán su desempeño para poder incluirlos o rechazarlos.

-Los estudiantes. Personas locales, jóvenes fácilmente identificables que se reúnen aparte y se distancian del grupo. No son de interés de las anteriores categorías, se los excluye del conocimiento total, sólo son observadores, oyentes que a medida que su participación sea más constante (tengan que entregar más "sacrificios") y su conocimiento académico sea mayor (tendrán que pasar por varias pruebas que parten de la licenciatura, hasta el doctorado en un tierra lejana) es que podrán ascender de categoría, de "status social".

En los recesos es que esta segmentación se hace notoria, llevados a cabo en la terraza del Palacio de Simón I. Patiño (cerrada esos días para no perturbar el encuentro). En el café de media tarde o en el refrigerio de media mañana vemos a un lado el grupo de los investigadores que pertenecen al Perú, Chile, Argentina y uno que otro boliviano (que se cuentan con los dedos de una mano); más allá están los extranjeros, franceses, alemanes, estadounidenses, etc. que se hablan en idiomas de origen anglosajón, también vemos grupos mixtos que se incrementan los últimos días y por último, relegados de tales conversaciones trascendentales sobre identidad indígena, sitios arqueológicos, textiles, documentos, otros congresos y felicitaciones a los exponentes, están los oyentes locales. Es decir, los estudiantes universitarios que se juntan entre ellos, con una apariencia reconocible y cierto temor o timidez en los ojos, casi conscientes de que no pertenecen allí y que nadie está dispuesto a "hacerlos pertenecer", no han dado suficientes ofrendas y no se han iniciado en el saber mítico por completo; este grupo de los relegados se compone de aquellos que no conocen a las figuras principales y éstas no hacen ningún esfuerzo por acercarse a los desconocidos cuando se enteran de su procedencia: no son, ni ellos mismos ni la academia en la que se forman, suficientemente extranjeros, suficientemente prestigiosos. En este ambiente la trayectoria lo es todo, por lo que no existe apertura real a lo nuevo, lo joven y fresco.

Pero cuando la comunidad se ajusta, lentamente en el transcurso de los días, aparecen objetos que, simbólicamente, reafirman las diferencias; por supuesto que el círculo de las huacas debe reafirmar su poderío que ha quedado un tanto difuso por la convivencia: tres o cuatro libros que desde la organización se donan sólo a los expositores. Con esto queda marcado el elitismo del "conocimiento" que se presumía a un principio. ¿Acaso no todos quienes han dado su "ofrenda" están interesados en los temas tratados? La sola presencia de los oyentes lo confirma, pero este tipo de saber, tal cual un mito secreto que se transmite de forma selectiva, sólo parece servir, interesar y difundirse entre el grupo de los "chamanes", de los sabios que preservan celosamente sus saberes del grupo general, de los "no iniciados" dentro de esta pequeña y esporádica comunidad.

Es sorprendente la discriminación sufrida por estudiantes, docentes e investigadores bolivianos en general (los pocos que se encuentran), no hay ningún interés en nosotros a 
menos que volvamos a nuestras comunidades, pueblos, mercados y cotidianidad en sí y estemos dispuestos a ser "sujetos de estudio", lamentablemente seguimos en ese papel exótico que les impide a estos "otros" reconocernos como colegas y personas en el mismo nivel intelectual. Lo triste es que en la testera de la inauguración el rector de la Universidad San Simón, la directora de la Fundación Cultural y el Oficial de Culturas les rinden su homenaje, mientras a lo largo de la mañana el "círculo de amigos" se homenajea entre ellos: reconocen a Teresa Gisbert, a Waldermar Espinoza y a Verónica Cerezeda; nombres conocidos, viejos, las "huacas sagradas" en la mitología en que se sustentan.

En las conferencias la metodología europea occidental ya caduca, se sigue tratando, la exoticidad sigue vigente, todo es sobre el indígena: el de hoy y el de ayer, lo que se lee y los vestigios que se encuentran sobre él, siempre con el tema de la veracidad dentro del lenguaje técnico y académico y la eterna discusión del "era así...no era así". Los Andes y las Tierras Bajas fueron las regiones escogidas, pero esta amplia delimitación parece ser sinónimo exclusivo de lo indígena; lo urbano, las transformaciones sociales, las apropiaciones culturales, parecen, en el imaginario de esta mítica académica, no pertenecer a los lugares geográficos antes mencionados y lo paradójico es que en las mesas de conferencia no tenemos un solo representante indígena de las comunidades y de los lugares que se tomaron en cuenta.

Cabe recalcar la poca presencia boliviana en las ponencias: de 53 ponenecias programadas sólo un $11 \%$ correspondía a participación "activa" boliviana, $56 \%$ de participación sudamericana y $33 \%$ de participación europea y estadounidense (se incluye una ponencia de un representante del Japón), y a muchos de ellos no se les entiende el español (idioma oficial del Estado Plurinacional, junto con otras 35 lenguas que no figuran una sola vez), usando traductores para la realización de sus escritos, no así en la exposición oral.

Combès se preguntaba sobre la veracidad de la interpretación en los "restos materiales" (Cómbes, 2015), con María de los Ángeles Muñoz enfatizaban en la falta de los estudios interdisciplinarios (Muñoz, 2015), Bruce Mannheim hacía una distinción entre lo egocéntrico y lo alocéntrico en las lenguas occidental y quechua (Mannhein, 2015) y más allá de las curiosidades que nos entregan los investigadores en fragmentos de incongruencia hacia una totalidad, cabe preguntarse si el lenguaje académico (egocéntrico, como diría Bruce) al momento de tratar culturas de estructura alocéntrica (como es el caso de los pueblos en los Andes) pondría en evidencia la existencia de un gran sesgo de entendimiento.

Esto se constituiría en un espacio de separación entre investigadores y comunidades (el problema de la "otredad" en la interpretación que ya planteaba Köping, 1993:14) que jamás podrían subsanarse, entonces estas curiosidades que nos presentan ¿no es acaso fruto de una ficcionalización argumentada de los mismos estudiosos? "Literatura de lo veraz", me atrevo a decir, que no posee ningún otro fin que deleitar a los lectores y oyentes, que son a la vez otros escritores y exponentes, y se cierra el círculo, enfatizado en la verdad de una serpiente que se muerde su propia cola, pues la "verdad científica" convertida en flameante bandera no encuentra cabida en el espacio de lo real, o de lo imaginario, o del entendimiento, en ningún espacio que no sean estas lecturas sobre la testera.

Los trabajos sociales, históricos, arqueológicos y culturales deberían socializarse más allá del "círculo de amigos", de la élite que puede comprar los libros, que tiene contraseñas de grandes bibliotecas virtuales extranjeras, de los pocos que pueden presentar su "ofrenda" (dinero y tiempo) para asistir a estos encuentros, conferencias y congresos, de una élite que tiene acceso al mal universalmente aceptado del financiamiento para realizar sus investigaciones, la mayoría en Bolivia, y uno se cuestiona: ¿Por qué Bolivia?, ¿por qué estos estudiosos no vuelven a sus países a estudiarse a sí mismos?, ¿qué insana curiosidad los impulsa a escaparse del occidente a querer experimentar una nueva vida y nuevas costumbres en nuestras regiones? El afán de "descubrir la pólvora", copando espacios laborales bajo una venia de la inversión extranjera y un mejor (¿o sobrevalorado?) sistema académico de 
universidades, dejando de lado a los investigadores bolivianos que ya saben sobre la pólvora, que pueden otorgar, sin duda y sin caer en la exoticidad, una visión más propia y menos etnocentrista (eurocentrista) de sí mismos. Aquí nos acercamos un poco, sólo un poco a las rupturas epistémicas que con tanta necesidad piden los países del Sur (De Soussa 2006 y Grofoguel, 2011).

Pero, como diría Alison Speeding: "La mayoría de aquellos investigadores que escriben en la lengua imperial aseveran estar a favor de las masas oprimidas, las etnias discriminadas y los habitantes pobres del Sur, quienes, paradójicamente, jamás podrán leer esos textos que abogan por su liberación" (Spedding, 2006: 188).

El trabajo del antropólogo (y también de historiados y arqueólogos) se resume en hacer familiar lo que en un principio le parece exótico. En esta relación de acercamiento/distanciamiento que plantean Boivin, Rosato y Arribas (1999: 195-214), es donde se problematiza la cuestión de lo subjetivo/objetivo, en su extrañamiento el antropólogo percibe objetivamente la conciencia práctica del "otro", pero en esa objetividad percibe siempre a través de su propia subjetividad, es decir, de su propia conciencia práctica. Es así que ambos, exoticidad y familiaridad son importantes para la investigación antropológica, inclusive si la investigación es de la cultura propia, ésta debe primero extrañarnos y luego familiarizarnos de nuevo con ella.

Lamentablemente estas personas de origen local, con su infinita capacidad, tienen dos opciones: buscar una beca en uno de estos países extranjeros, para embeberse en teorías y metodologías occidentales y recién volver a Bolivia a trabajar en su área o conseguir otro trabajo, una historia larga de carreras truncadas por el bajo presupuesto para sociales y humanidades y la falta de trabajo, porque el área está copada por las mismas personas de hace veinte años. La situación económica empuja a buscar nuevos espacios, trabajos mediocres y sobreexplotados, dejando la carrera profesional como un sueño juvenil y a aquellos con amor profundo a su trabajo sólo les queda mover cielo y montañas para al auto financiamiento y para dejarse robar por las editoriales.

Es en ese afán, de construir una nueva etnografía no exótica que pongo en este trabajo a los estudiosos en el lugar que tanto tiempo nos han puesto a nosotros, en el de: "sujeto de estudio". Una vez realizada la investigación en los seis días que duró el evento se llega a una única conclusión a partir de esta experiencia y otras similares: Basta.

Basta de congresos y encuentros excluyentes, cuyos resultados rara vez llegan a los actores sociales, al ámbito político y a los espacios cotidianos.

Basta de trabajos de investigación cuyo único propósito sea acumularse en los aparadores de las librerías debido a su alto precio y de reactualizar a los mismos miembros de la élite.

Basta, al fin, del etnocentrismo en las ciencias sociales, de las camarillas que no dejan espacio a las nuevas mentes y a los nuevos aportes, de "huacas sagradas", de los grandes investigadores de renombre que se constituyen en poseedores de la "verdad" y cuya figura evoca para los más jóvenes a inalcanzables e intocables "chamanes del saber único y verdadero".

Es hora de democratizar el conocimiento, los resultados y convocatorias de las investigaciones, de dar un giro epistemológico de las ciencias, que los nuevos y viejos saberes se entrecrucen en espacios de diálogo e intercambio reales, sin segmentaciones económicas, laborales, culturales, raciales ni académicas.

\section{Bibliografía}

BOIVIN M., ROSATO A. y ARRIBAS V. (1999). "La observación participante". En Construcciones de otredad. Ed. Eudeba. P.p. 195-214.

COMBÈS, Isabelle. (2015). "Diálogo de sordos en Santa Cruz la Vieja". En Encuentro In- 
ternacional "Arqueología y Etnohistoria en los Andes y Tierras Bajas. Dilemas y Miradas Complementarias". Cochabamba, Bolivia.

DE SOUSA SANTOS, Boaventura. (2006) Renovar la teoría crítica y reinventar la emancipación social (encuentros en Buenos Aires). CLACSO: Buenos Aires.

- (2002) Hacia una concepción multicultural de los derechos humanos. EL OTRO DERECHO, número 28. Julio de 2002. ILSA, Bogotá D.C., Colombia. P.p. 59-84.

GROSFOGUEL, Ramón. (2011) La Descolonización del Conocimiento: Diálogo Crítico entre la Visión Descolonial de Frantz Fanon y la Sociología Descolonial De Boaventura De Sousa Santos. 97-108. IV Training Seminar del Foro de Jóvenes Investigadores en Dinámicas Interculturales (FJIDI)" del Centro de Estudios y Documentación Internacionales de Barcelona (CIDOB). Barcelona.

GUBER, Rosana. (2001). "La Etnografía: Método, Campo y Reflexividad". Buenos Aires: Grupo Norma.

HAMMERSLEY, Martín; ATKINSON, Paul. (1994). "Etnografía. Métodos de Investiga-

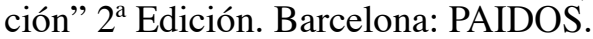

KÖPING, Klaus Peter. (1993). "La ética en la práctica etnográfica: Entre el universalismo y autonomía pluralista" $2^{a}$ Edición. Berlín: Dietrich Reimer Verlag.

MANNHEIM, Bruce. (2015). "El marco de referencia y la formación de sujetos sociales". En: Encuentro Internacional "Arqueología y Etnohistoria en los Andes y Tierras Bajas. Dilemas y Miradas Complementarias". Cochabamba, Bolivia

MUÑOZ, María de los Ângeles. (2015). “Arqueología y Etnohistoria; encuentros, desencuentros y posibilidades metodológicas". En Encuentro Internacional "Arqueología y Etnohistoria en los Andes y Tierras Bajas. Dilemas y Miradas Complementarias". Cochabamba, Bolivia

SPEDDING, Alison. (2006). "Las fronteras del pensamiento fronterizo". En: Yapu, M.(comp.). Modernidad y pensamiento descolonizador. Memoria Seminario Internacional. La Paz: Fundación PIEB/Instituto Francés de Estudios Andinos IFEA. 